\title{
EXTENDED SLEEVE LOBECTOMY FOR LUNG CANCER: THE AVOIDANCE OF PNEUMONECTOMY
}

Morihito Okada, MD

Noriaki Tsubota, MD

Masahiro Yoshimura, MD

Yoshifumi Miyamoto, MD

Hidehito Matsuoka, MD,

Shinsuke Satake, MD

Hiroyuki Yamagishi, MD
Objective: We have tried atypical bronchoplasties in patients with noncompromised lung function with centrally located cancers to avoid pneumonectomy. We evaluated the efficacy of extended sleeve lobectomy in such patients. Methods: Among 157 patients undergoing bronchoplasty for primary non-small cell lung carcinoma, 15 patients underwent extended sleeve lobectomy. Results: According to the mode of reconstruction, the 15 patients were classified into 3 groups: (A) anastomosis between the right main and lower bronchi with resection of the upper and middle lobes $(n=6),(B)$ anastomosis between the left main and basal segmental bronchi with resection of the upper lobe and superior segment of the lower lobe $(n=4)$, and $(C)$ anastomosis between the left main and upper division bronchi with resection of the lingular segment and lower lobe $(n=5)$. The tumors were completely resected in all patients. Pulmonary angioplasty was carried out in 8 patients. Bronchial reconstruction was successful in all patients. Pulmonary vein thrombosis resulting from overstretching of the inferior pulmonary vein occurred in 1 patient of group $A$ and was relieved by completion pneumonectomy. There was neither operative mortality nor local recurrence. Although all patients with stage IIB disease and half of patients with stage IIIA disease were alive without recurrence (12-106 months), half of the patients with stage IIIA disease died of distant metastases within 1 year. Conclusions: We suggest that this extended sleeve lobectomy, which is technically demanding, should be considered in patients with centrally located lung cancer, because this lung-saving operation is safer than pneumonectomy and is equally curative. (J Thorac Cardiovasc Surg 1999;118:710-4)
T he risk of perioperative mortality and morbidity is greater for pneumonectomy than for smaller pulmonary resections. Some authors have reported that the 30-day operative mortality rate after pneumonectomy is approximately $6 \%$ to $7 \% .^{1-3}$ Moreover, we believe that pneumonectomy is a disease in itself and should be avoided at all costs because of the long-term complications that are sometimes associated with pneumonectomy but seldom seen after lobectomy or sleeve lobecto-

From the Department of Thoracic Surgery, Hyogo Medical Center for Adults, Akashi, and National Hyogo Central Hospital, Sanda, Hyogo, Japan.

Received for publication May 3, 1999; revisions requested June 3, 1999; revisions received July 6, 1999; accepted for publication July 13, 1999.

Address for reprints: Noriaki Tsubota, MD, Department of Thoracic Surgery, Hyogo Medical Center for Adults, Kitaohji-cho13-70, Akashi City 673, Hyogo, Japan (E-mail: n-tsubo@sanynet.ne.jp). Copyright (C) 1999 by Mosby, Inc.

$0022-5223 / 99 \$ 8.00+0 \quad \mathbf{1 2 / 1 / 1 0 1 4 1 7}$ my, that is, the so-called postpneumonectomy syndrome presenting as late pulmonary hypertension or respiratory failure.

Bronchoplasty was originally designed for patients with compromised lung function unable to tolerate pneumonectomy. Since sleeve lobectomy yielded survival results at least equal to those of pneumonectomy, as well as better functional results, it became an accepted procedure for patients with lung cancer who have anatomically suitable tumors, regardless of lung function. ${ }^{4-7}$ Functional lung parenchyma can be preserved, and the reimplanted lobes contribute to postoperative quality of life. If a second primary lung cancer develops, subsequent resection may be offered to selected patients. ${ }^{8,9}$ Although in most cases sleeve lobectomy may involve resection of one lobe or of the right middle and lower lobes, we have tried various complex atypical resections for patients with noncompromised lung function and larger centrally located tumors to avoid pneumonectomy. This study summarizes our experi- 


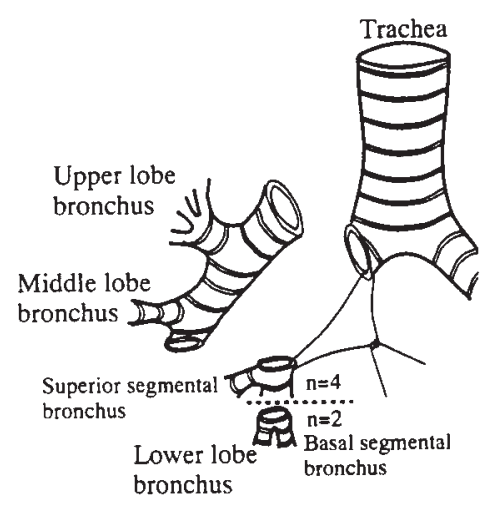

$$
\underset{(\mathrm{n}=6)}{\operatorname{Type} A}
$$
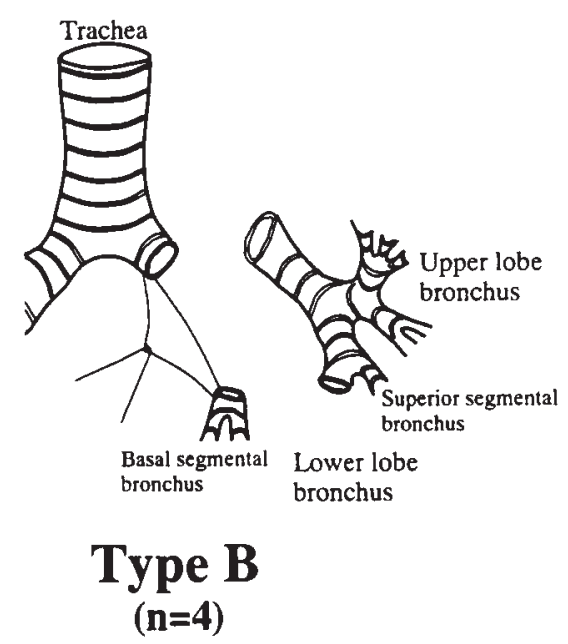

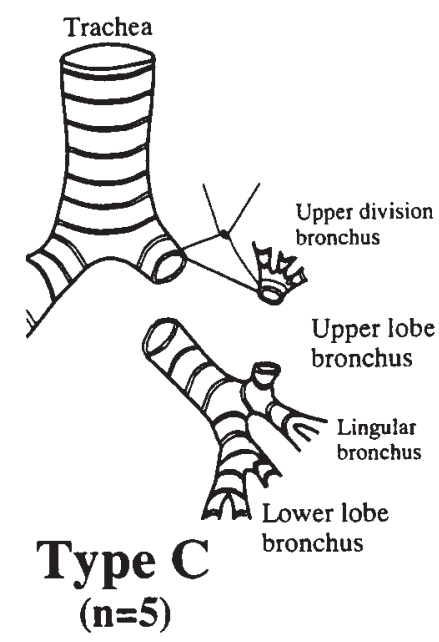

Fig 1. Sketches of the bronchial reconstruction.

Table I. Type of the procedure and reconstruction

\begin{tabular}{llll}
\hline Classification & Lung resection & Anastomosis & Preservation \\
\hline Type A & Rt. upper + middle bilobectomy (+S6) & Rt. main br.-lower lobe br. & Rt. lower lobe (Rt. basal segment) \\
& Lt. upper lobectomy + S6 segmentectomy & (Rt. main br.-basal segmental br.) & Lt. main br.-basal segmental br. \\
Type B & Lt. lower lobectomy + lingulectomy & Lt. main br.-upper division br. & Lt. upper division of upper lobe \\
Type C & &
\end{tabular}

Rt., Right: Lt., left; $b r$., bronchus; S6, superior segment of the lower lobe.

ence with complex bronchial reconstruction and stresses the importance of lung-preserving operations.

\section{Patients and methods}

Among 1345 patients who were operated on for primary lung cancer from January 1985 to December 1998, 157 bronchoplastic procedures (11.7\%) for non-small cell lung cancer were carried out. The patients undergoing atypical extended sleeve lobectomy were selected from this series and classified into 3 groups (A to $\mathrm{C}$ ) according to the mode of reconstruction (Table I, Fig 1).

Standard surgical technique was used for lobectomy and segmentectomy until the bronchus was encountered. Proximal and distal points of transection were determined with at least $1 \mathrm{~cm}$ of the macroscopically unaffected distance of the bronchus. Additional pieces of proximal and distal margin were removed for frozen section evaluation. In this type of bronchoplasty, the two bronchial stumps usually differ in size, and the distal one is quite thin and frail. A couple of adjusting stitches in the membranous part of the larger stump may help to make the anastomosis easier to perform. Inside knotting of the deepest stitches is helpful even at distal levels beyond the lobar bronchus. ${ }^{7}$ Anastomosis is performed with interrupted sutures and full-thickness bites using 4-0 monofilament absorbable material. The sutures are placed and tied in order from the deepest point to the lateral direc- tion. When angioplasty is also necessary, which is often encountered in types A and B, both the bronchial and arterial anastomotic sites should be separated.

The choice of operative procedure was based on curative intent while preserving as much functional lung volume as possible. ${ }^{8}$ Routine systematic dissection of all the hilar and mediastinal nodes was performed in every case. ${ }^{10}$ Because of the potential for complications of bronchial and arterial anastomoses, special precautions were taken to cover them with a pedicled substernal fat pad. Postoperatively, nasotracheal suction was carried out routinely to clear the airways. In patients in whom auscultation or radiography was suggestive of retention of secretions, bronchoscopic therapy was performed.

Preoperative pulmonary function studies were done to determine first-second forced expiratory volume. In addition, quantitative ventilation radionuclide scans and arterial blood gas analyses were performed. Furthermore, the results of these lung function tests at 4 to 6 months after the operation were compared with the preoperative values.

In patients receiving induction therapy, the regimen consisted in 2 cycles of vindesine sulfate, mitomycin, and cisplatin given intravenously at 4 -week intervals. In patients receiving preoperative irradiation, radiotherapy to the primary tumor and mediastinum was concurrently delivered until the patient had received a cumulative dose of $40 \mathrm{~Gy}$. After the operation, none of the patients was subjected to additional 


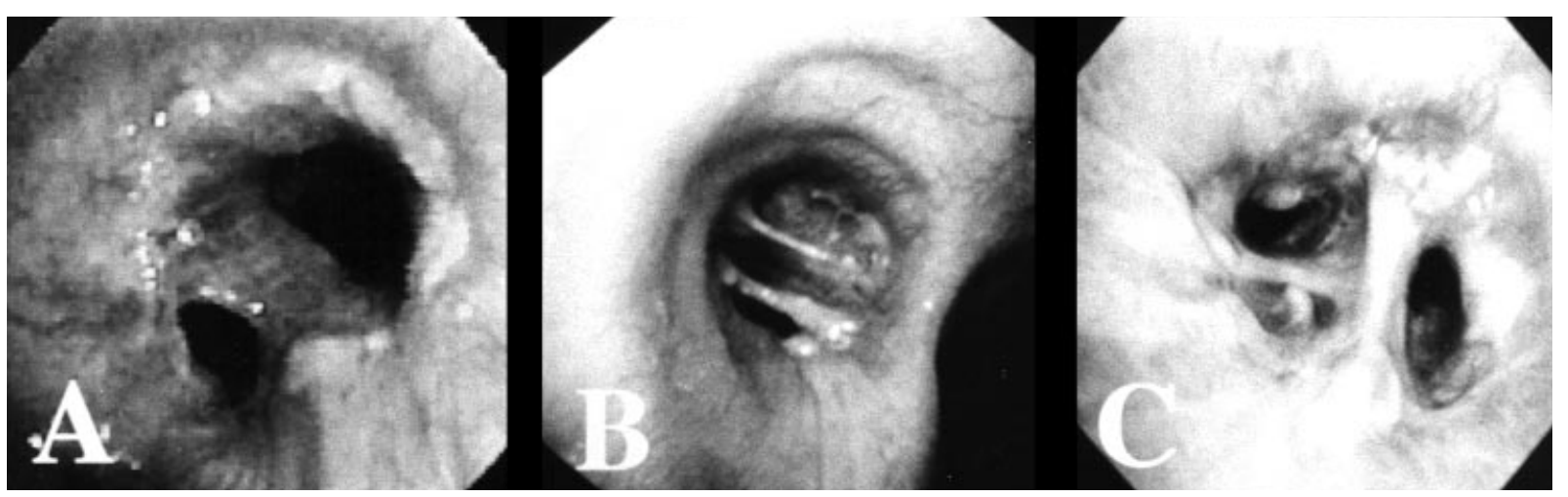

Fig 2. Postoperative bronchoscopic findings showing bronchial anastomosis. A, Case A-5, the bifurcation of the right basal segmental bronchus; B, case B-2, the trifurcation of the left basal segmental bronchus and the right main bronchus; $\mathbf{C}$, case $\mathbf{C}-1$, the bifurcation of the left upper division.

Table II. Case data

\begin{tabular}{|c|c|c|c|c|c|c|c|c|c|c|c|}
\hline \multirow[b]{2}{*}{ Type } & \multirow{2}{*}{$\begin{array}{l}\text { Patient No. } \\
\text { (sex, age [y]) }\end{array}$} & \multicolumn{2}{|c|}{ Preoperative } & \multirow[b]{2}{*}{ Histology } & \multirow{2}{*}{$\begin{array}{l}\text { Induction } \\
\text { therapy }\end{array}$} & \multirow{2}{*}{$\begin{array}{c}P A \\
\text { reconstruction }\end{array}$} & \multirow[b]{2}{*}{ Result } & \multicolumn{2}{|c|}{ Pathologic } & \multirow{2}{*}{$\begin{array}{l}\text { Local } \\
\text { recurrence }\end{array}$} & \multirow[b]{2}{*}{ Prognosis } \\
\hline & & Staging & $T N M$ & & & & & Staging & $T N M$ & & \\
\hline \multirow[t]{6}{*}{ A } & $1(\mathrm{M}, 66)$ & IIIA & 310 & $\mathrm{AD}$ & + & + & Poor & IIIA & 320 & No & $12 \mathrm{mo}$, dead* \\
\hline & $2(\mathrm{M}, 62)$ & IIIA & 310 & SQ & + & + & Good & IIIA & 310 & No & $12 \mathrm{mo}$, dead* \\
\hline & $3(\mathrm{M}, 71)$ & IIB & 300 & SQ & - & - & Good & IIB & 300 & No & $106 \mathrm{mo}$, alive \\
\hline & $4(\mathrm{M}, 58)$ & IIIA & 310 & SQ & - & + & Good & IIIA & 310 & No & $46 \mathrm{mo}$, alive \\
\hline & $5(\mathrm{~F}, 51)$ & IIIA & 320 & SQ & + & + & Good & IIB & 210 & No & $12 \mathrm{mo}$, alive \\
\hline & $6(\mathrm{~F}, 61)$ & IIIA & 310 & $\mathrm{AD}$ & - & + & Good & IIIA & 320 & No & 36 mo, alive \\
\hline \multirow[t]{4}{*}{ B } & $1(\mathrm{M}, 72)$ & IIB & 310 & SQ & - & + & Good & IIB & 210 & No & $60 \mathrm{mo}$, alive \\
\hline & 2 (M. 65) & IIIA & 310 & SQ & - & + & Good & IIIA & 310 & No & $51 \mathrm{mo}$, alive \\
\hline & $3(\mathrm{M}, 64)$ & IIB & 300 & SQ & - & - & Good & IIB & 300 & No & $37 \mathrm{mo}$, alive \\
\hline & $4(\mathrm{M}, 70)$ & IIB & 210 & SQ & - & + & Good & IIB & 210 & No & $27 \mathrm{mo}$, alive \\
\hline \multirow[t]{5}{*}{$\mathrm{C}$} & $1(\mathrm{M}, 64)$ & IIB & 310 & SQ & - & - & Good & IIB & 210 & No & $68 \mathrm{mo}$, alive \\
\hline & $2(\mathrm{M}, 68)$ & IIB & 310 & SQ & - & - & Good & IIB & 210 & No & $66 \mathrm{mo}$, alive \\
\hline & $3(\mathrm{M}, 66)$ & IIIA & 220 & SQ & + & - & Good & IIIA & 120 & No & 9 mo, dead* \\
\hline & $4(\mathrm{M}, 56)$ & IIB & 300 & SQ & - & - & Good & IIB & 300 & No & $15 \mathrm{mo}$, alive \\
\hline & $5(\mathrm{M}, 62)$ & IIB & 310 & SQ & - & - & Good & IIB & 210 & No & $10 \mathrm{mo}$, alive \\
\hline
\end{tabular}

$P A$, Pulmonary artery; $A-1$ and $A-5$, anastomosis between right main bronchus and basal segmental bronchus; $A D$, adenocarcinoma; $S Q$, squamous cell carcinoma. "Due to distant metastasis.

chemotherapy or radiotherapy. Routine bronchoscopic examinations were performed at 1 and 6 months after operation to rule out local recurrence. All patients had a chest radiograph, a computed tomographic scan of the chest, and a physical examination during the follow-up visits, which took place at least twice a year. Resected specimens were examined histopathologically and histologic typing was done according to the World Health Organization classification. ${ }^{11}$ Surgicalpathologic staging was assigned according to the New International Staging System for Lung Cancer. ${ }^{12}$

\section{Results}

Extended sleeve lobectomy was performed in 15 patients (Table II). On the basis of clinical and objec- tive functional assessment, all patients were considered to have adequate pulmonary function to tolerate pneumonectomy. The group comprised 13 men and 2 women with a mean age of 64 years (range, 51-72 years). Overall follow-up ranged from 9 to 106 months. The histopathologic diagnosis was squamous cell carcinoma in $13(87 \%)$ and adenocarcinoma in $2(13 \%)$ patients. Four $(27 \%)$ patients received induction therapy. Complete resection was performed in all patients. Pulmonary angioplasty, so-called double sleeve resection, was carried out in 8 patients and performed frequently in types A and B $(8 / 10,80 \%)$. Concerning surgical-pathologic staging, 9 patients $(60 \%)$ had stage IIB disease and 6 patients had stage IIIA disease. There 
was no operative mortality, which was defined as death within 30 days after the operation. Bronchial reconstruction was successful in all patients (Fig 2). Postoperative complications during hospitalization were infrequent and nonfatal. Acute deterioration associated with massive pulmonary vein thrombosis occurred in 1 patient (A-1), as a result of overstretching of the inferior pulmonary vein and was relieved by completion pneumonectomy. Pneumonia occurred in 2 patients, who were managed conservatively. No cases of anastomotic stenosis developed.

No local recurrence developed on the intrathoracic fields, including the anastomotic sites, reimplanted lung, or lymph nodes. All patients with stage IIB disease and half of the patients with stage IIIA disease were alive without recurrence at the time of this report. However, half of patients with stage IIIA disease died within 1 year of distant metastases (Table II).

Regarding lung function, first-second forced expiratory volume decreased from $1.92 \pm 0.51 \mathrm{~L}$ before the operation to $1.74 \pm 0.43 \mathrm{~L}$ after the operation $(n=11)$, showing that functional loss of the lung was minimal. Arterial oxygen pressure increased from $77.0 \pm 8.1 \mathrm{~mm}$ $\mathrm{Hg}$ to $85.0 \pm 11.2 \mathrm{~mm} \mathrm{Hg}(\mathrm{n}=13)$, indicating some amelioration of hypoxia with the operation as the turning point. Postoperative quantitative ventilation radionuclide scans revealed that the lung ratio on the side of the operation (operated lung/nonoperated lung) was $26 \% \pm 18 \%(n=11)$. This value would have been $0 \%$ if pneumonectomy had been performed instead.

\section{Discussion}

Bronchoplasty is accepted as appropriate for selected patients with resectable malignant tumors and presents an alternative to the otherwise unavoidable pneumonectomy. One should remember that the decision to perform bronchoplasty for a malignant tumor depends on a subtle balance between postoperative quality of life and the risk of recurrence plus postoperative complications. One possible problem of bronchoplasty for malignant disease is the potentially increased rate of local recurrence. The review by Tedder and associates ${ }^{5}$ showed that the local recurrence rate after sleeve lobectomy was $12.5 \%$ (84/673), although most authors did not specify whether local recurrence developed at the suture line or within the thorax. In this series, local recurrence could not be found either in the intrathoracic lymph nodes or in pulmonary sites. Until recently, this procedure usually was mainly indicated for patients with a compromised lung reserve. ${ }^{4,5,13} \mathrm{We}$, however, performed it frequently and actively not only in patients with compromised lung function but also in those with non- compromised lung function. ${ }^{14}$ Although bronchoplastic procedures were reported to be appropriate for approximately $5 \%$ to $8 \%$ of patients with a resectable malignant pulmonary tumor, ${ }^{5,15}$ we could apply this procedure in $11.7 \%(157 / 1345)$ of our patients. In any case, it is essential to keep a macroscopically sufficient margin of safety, as well as to perform a rapid frozen section analysis during the operation.

Because we always keep lung-saving procedures in mind, pneumonectomy has been performed infrequently and much less than sleeve lobectomy. Also, compared with pneumonectomy, sleeve lobectomy is not associated with an increase in local recurrence. In consequence, we have fewer early postoperative complications such as pneumonia, pulmonary infarction, or pulmonary edema, and curative resection can be done with a low operative mortality. ${ }^{8,10,16}$ Pneumonectomy, which limits pulmonary reserve and results in an increased pulmonary artery pressures, results in greater long-term cardiopulmonary disability and worse quality of life than standard lobectomy or sleeve lobectomy. ${ }^{17}$ Pneumonectomy has been considered to be a predisposing, but not exclusively causative, factor for cardiopulmonary death. ${ }^{18} \mathrm{We}$ consider that pneumonectomy is a disease in itself and should be avoided at all costs. Although most surgeons might have selected pneumonectomy for the patients in this series, we tried to resect as little lung tissue as possible and performed lung-preserving operations involving anastomosis between the main bronchus and the segmental bronchus.

The complication rate in the present series was low, local recurrence did not occur, and the survival was acceptable. In 1 patient, pulmonary vein thrombosis occurred at the level where the reconstructed basal segment, accompanied by sleeve angioplasty of the pulmonary artery, had been pulled up with tension on the carina. Learning from this case, we avoided this type of complication by performing a pericardial incision around the inferior pulmonary vein.

Invasion of the bronchus by central tumor, in association with normal nodes, was the most suitable indication. More recently, several reports have shown acceptable long-term results for sleeve resection of lung cancer with N1 disease but not with N2 disease. ${ }^{19,20}$ None of the patients in our series had local recurrence, indicating a satisfactory local control of central lung cancer by this extended sleeve lobectomy, which saved the portion of the lobes not involved with the tumor. The indication for sleeve resection in patients with $\mathrm{N} 2$ disease (stage IIIA) is controversial and requires circumspection. However, we do not think that pneumonectomy instead of sleeve lobectomy would have resulted in 
better survival for patients with $\mathrm{N} 1$ or $\mathrm{N} 2$ disease, because most patients died of distant metastases.

The results of this study clearly reveal that extended sleeve lobectomy is a satisfactory surgical treatment for lung cancer in terms of operative risk, curability, and lung function after the operation. The indications for this procedure for lung cancer, which is technically more demanding than pneumonectomy, have to be clarified, and the decision to select this procedure may be influenced by the surgeon's skills. However, we suggest that this extended sleeve lobectomy should be performed for centrally located lung cancer whenever feasible, since this procedure eradicated cancer to a degree similar to that of pneumonectomy and offered the possible advantages of lower operative mortality rates, equal if not better survival, and improved quality of life.

\section{REFERENCES}

1. Ginsberg RJ, Hill LD, Eagan RT, Thomas P, Mountain CF, Deslauriers J, et al. Modern thirty-day operative mortality for surgical resections in lung cancer. J Thorac Cardiovasc Surg 1983; 86:654-8.

2. Deneffe G, Lacquet LM, Verbeken E, Vermaut G. Surgical treatment of bronchogenic carcinoma: a retrospective study of 720 thoracotomies. Ann Thorac Surg 1988;45:380-3.

3. Kadri MA, Dussek JE. Survival and prognosis following resection of primary non-small cell bronchogenic carcinoma. Eur J Cardiothorac Surg 1991;5:132-6.

4. Weisel R, Cooper JD, Delarue NC, Theman TE, Todd TRJ, Pearson FG. Sleeve lobectomy for carcinoma of the lung. J Thorac Cardiovasc Surg 1979;78:839-44.

5. Tedder M, Anstadt M, Tedder S, Lowe JM. Current morbidity, mortality, and survival after bronchoplastic procedures for malignancy. Ann Thorac Surg 1992;54:387-91.

6. Van Schil PE, Riviere AB, Knaepen PJ, Swieten HA, Defauw JJ, Bosch JM. TMN staging and long-term follow-up after sleeve resection for bronchogenic tumors. Ann Thorac Surg 1992;52: 1096-1101.

7. Tsubota N, Yoshimura M, Murotani A, Miyamoto Y, Matoba Y.
One hundred and one cases of bronchoplasty for primary lung cancer. Surg Today 1994;24:978-81.

8. Okada M, Tsubota N, Yoshimura M, Miyamoto Y. Surgical approach for multiple primary lung carcinomas. J Thorac Cardiovasc Surg 1998;115:836-40.

9. Van Schil PE, Riviere AB, Knaepen PJ, Swieten HA, Defauw JJ, Bosch JM. Second primary lung cancer after bronchial sleeve resection: treatment and results in eleven patients. J Thorac Cardiovasc Surg 1992;104:1451-5.

10. Okada M, Tsubota N, Yoshimura M, Miyamoto Y. Proposal for reasonable mediastinal lymphadenectomy in bronchogenic carcinomas: role of subcarinal node in selective dissection. J Thorac Cardiovasc Surg 1998;116:949-53.

11. World Heath Organization histologic typing of lung tumours. 2nd ed. Am J Clin Pathol 1982;77:123-36.

12. Mountain CF. Revisions in the international system for staging lung cancer. Chest 1997;111:1710-7.

13. Bennet FW, Smith AR. A twenty-year analysis of the results of sleeve resection for primary bronchogenic carcinoma. J Thorac Cardiovasc Surg 1978;76:840-5.

14. Okada M, Nakai R, Yamagishi H, Satake S, Yamamoto H. Right upper and middle sleeve bilobectomy with atypical pulmonary arterioplasty. Jpn J Thorac Cardiovasc Surg 1999;47:121-3.

15. Lowe JE, Sabiston DC Jr. Bronchoplastic techniques in the surgical management of benign and malignant pulmonary lesions. In: Sabiston DC Jr, Spencer FC, editors. Surgery of the chest. Philadelphia: WB Saunders; 1990. p. 577.

16. Okada M, Tsubota N, Yoshimura M, Miyamoto Y, Matsuoka H. Prognosis of completely resected pN2 non-small cell lung carcinomas: What is the significant node that affects survival? J Thorac Cardiovasc Surg 1999;118:270-5.

17. Rocco PM, Antkowiak JG, Takita H, Urschel JD. Long-term outcome after pneumonectomy for nonsmall cell lung cancer. J Surg Oncol 1996;61:278-80.

18. Shields TW, Humphrey EW, Higgins GA, Keehn RJ. Long-term survivors after resection of lung carcinoma. J Thorac Cardiovasc Surg 1978;76:439-45.

19. Naruke T. Bronchoplastic and bronchovascular procedures of the tracheobronchial tree in the management of primary lung cancer. Chest 1989;96(Suppl):53S-6S.

20. Mehran RJ, Deslauriers J, Piraux M, Beaulieu M, Guimont C, Brisson J. Survival related to nodal status after sleeve resection for lung cancer. J Thorac Cardiovasc Surg 1994;107:576-83. 